\title{
Impact of laughter on air trapping in severe chronic obstructive lung disease
}

\author{
Martin H Brutsche' \\ Paul Grossman ${ }^{2}$ \\ Rebekka E Müller' \\ Jan Wiegand' \\ Pello ${ }^{3}$ \\ Florent Baty' \\ Willibald Ruch ${ }^{4}$ \\ 'Pneumology; ${ }^{2}$ Psycho-Somatic \\ Medicine, University Hospital Basel, \\ Petersgraben, Basel, Switzerland; \\ ${ }^{3}$ Pello, Clown, Basel, Switzerland; \\ ${ }^{4}$ Psychology, University of Zurich, \\ Department of Psychology, Zurich, \\ Switzerland
}

\begin{abstract}
Static and dynamic hyperinflation is an important factor of exertional dyspnea in patients with severe COPD. This proof-of-concept intervention trial sought to study whether laughter can reduce hyperinflation through repetitive expiratory efforts in patients with severe COPD. For small groups of patients with severe COPD $(n=19)$ and healthy controls $(n=10)$ Pello the clown performed a humor intervention triggering regular laughter. Plethysmography was done before and up to 24 hours after intervention. Laughing and smiling were quantified with video-analysis. Real-time breathing pattern was assessed with the LifeShirt ${ }^{\mathrm{TM}}$, and the psychological impact of the intervention was monitored with self-administered questionnaires. The intervention led to a reduction of TLC in COPD $(p=0.04)$, but not in controls $(p=0.9)$. TLC reduction was due to a decline of the residual volume. Four (22 [CI 95\% 7 to 46] \%) patients were $\geq 10 \%$ responders. The frequency of smiling and TLC at baseline were independent predictors of TLC response. The humor intervention improved cheerfulness, but not seriousness nor bad mood. In conclusion, smiling induced by a humor intervention was able to reduce hyperinflation in patients with severe COPD. A smiling-derived breathing technique might complement pursed-lips breathing in patients with symptomatic obstruction.
\end{abstract}

Keywords: bronchodilator, cheerfulness, COPD, dyspnoea, humor, hyperinflation

\section{Introduction}

Chronic obstructive lung disease (COPD) is characterized by static and dynamic air trapping leading to hyperinflation (Pauwels et al 2001). Hyperinflation with consecutive flattening of the diaphragm increases the respiratory effort and is an important mechanism responsible for dyspnoea in these patients. Different treatment strategies for COPD aim to reduce lung hyperinflation. Along these lines, the reduction of hyperinflation is the main effect of bronchodilators leading to symptomatic relief in patients with COPD. They improve the emptying of air in the distended terminal airspaces by dilating the bronchi. Lung volume reduction surgery is another example of the benefit for patients when reducing hyperinflation. It has not yet been studied whether laughter would be able to reduce lung volumes in patients with COPD. It could be speculated that the repetitive expiratory efforts would be able to do so. On the other hand, the increased minute ventilation during laughter could increase dynamic hyperinflation (O'Donnell et al 2001). Although bronchial hyperresponsiveness is not a typical feature of COPD, it can be observed in a significant proportion of patients with COPD (Brutsche et al 2006). The presence of bronchial hyperresponsiveness might lead to laughter-induced worsening of bronchial obstruction comparable to the situation in patients with asthma. Laughter is a recognized trigger for asthma attacks (Sarafino and Dillon 1998). Liangas and colleagues (2004) found that 44 of 105 patients reported laughter-induced asthma. Laughter-induced asthma was associated with poor asthma control in their study. It can be postulated that laughter might be harmful in combination with poorly controlled bronchial hyperresponsiveness 
(Herxheimer 1978). On the other hand, watching a humorous film led to a significant reduction of bronchial hyperresponsiveness to methacholine in a controlled trial in 20 asthmatic patients (Kimata 2004).

Filipelli and colleagues (2001) investigated the effects of fits of laughter in 11 healthy controls. They concluded that all fits of laughter were characterized by a sudden occurrence of repetitive expiratory efforts resulting in an immediate significant reduction of the functional residual capacity (FRC). Laughter was associated with excessively high intra-thoracic pressures, which were accompanied with significant dynamic airway compression. Whether the reduction of FRC would persist beyond a period of laughing was not investigated. There is neither another larger study, nor a study in patients with respiratory diseases confirming these results.

The aim of the current study was to investigate whether laughter in response to a humor intervention in patients with severe chronic airflow obstruction is safe and whether it can reduce static lung volumes beyond the period of laughter up to 24 hours. We compared the impact of laughter on the breathing pattern of patients with severe COPD and healthy controls. Furthermore, we observed the impact of such a humor intervention on the psychological wellbeing and its interaction with breathing pattern and the static lung volumes.

\section{Methods}

\section{Study population and conduct}

For this proof-on-concept intervention trial, 19 patients with severe to very severe chronic obstructive lung disease (GOLD III and IV) with documented irreversibility and 10 healthy controls were recruited and were willing to give informed consent. All participants were between 20 and 80 years of age. Healthy controls had to have normal lung functions, did not have any chronic disease and were not on any regular medication. All patients had to be on a disease severity-adapted treatment, and, indeed, all patients were on high-dose combined inhalation therapy with long-acting betaagonists, topical corticosteroids and thiotropium bromide. Some patients additionally had systemic corticosteroids, xanthine-derivates and/or long-term oxygen therapy.

Patients with COPD were told to continue their usual therapy until the evening before the study day, but withheld inhalation therapy during the entire study day. On arrival at the lung function laboratory participants underwent a baseline assessment including self-administered questionnaires (State-Trait Cheerfulness Inventory developed by Ruch and Köhler 1999; Pauwels et al 2001), spirometry and plethysmography. They then followed a humor intervention in small groups by a clown Pello (Figure 1). Participants were exposed to the intervention for a mean duration of 30 (range 20-60) minutes. During the intervention the participants were videotaped for the analysis of response in terms of mimic, posture and gesture. The videotapes were analyzed by the same psychologist trained in using the Facial Action Coding System (Ekman et al 2002) blinded for lung function results. Immediately ( $<3$ minutes), 2, 6, and 24 hours after the intervention they underwent a follow-up assessment with the self-administered questionnaires and plethysmography. The latter did not include any rapid maneuvers to minimize potential interaction with the outcome measures. Additionally, patients were equipped with an ambulatory device (LifeShirt $^{\circledR}$, software VivoLogic ${ }^{\circledR}$; both from VivoMetrix ${ }^{\circledR}$, Ventura/CA, USA; calibration with $800 \mathrm{~mL}$ calibration bag) able to measure real-time breathing during a baseline resting period of 15 minutes, the humor intervention, as well as a post-intervention resting period of 15 minutes. The study was approved by the local ethical review board (EKBB 24/05).

\section{Assessment of pulmonary function}

Measurements of static lung volumes and spirometry were done with body plethysmography (Total body master ${ }^{\circledR}$, Jaeger, Würzburg, Germany) and complied with American Thoracic Society recommendations (ATS 1991, 1995; Miller et al 2005). Diffusion capacity was assessed using a MSPFT (Jäger, Würzburg, Germany). A reduction of $\geq 10 \%$ calculated as \%-predicted value for the total lung capacity (TLC) was considered as biologically meaningful. Therefore, individuals with a decrease in TLC of $\geq 10 \%$, predicted, were taken as "responders".

\section{Statistical analysis}

According to the main hypothesis a change in total lung capacity was considered as the main outcome parameter. A sample size calculation based on a paired t-test power calculation showed that, assuming an intra-individual variability for TLC of 5\%, 17 subjects were necessary to have a power of $90 \%$ in order to detect a mean reduction of $10 \%$ in TLC. Data analysis was done according to intention-to-treat-principles using R (v. 2.2.1, R foundation for statistical computing, Vienna, Austria) and SPSS (v. 11, SPSS Inc, USA). Repeated measures analyses of variance and student's T-tests were done as appropriate. Significant variables from the univariate comparison between responders and non-responders derived from baseline lung functions (TLC at baseline), questionnaires (scores for cheerfulness, seriousness and bad mood), and 


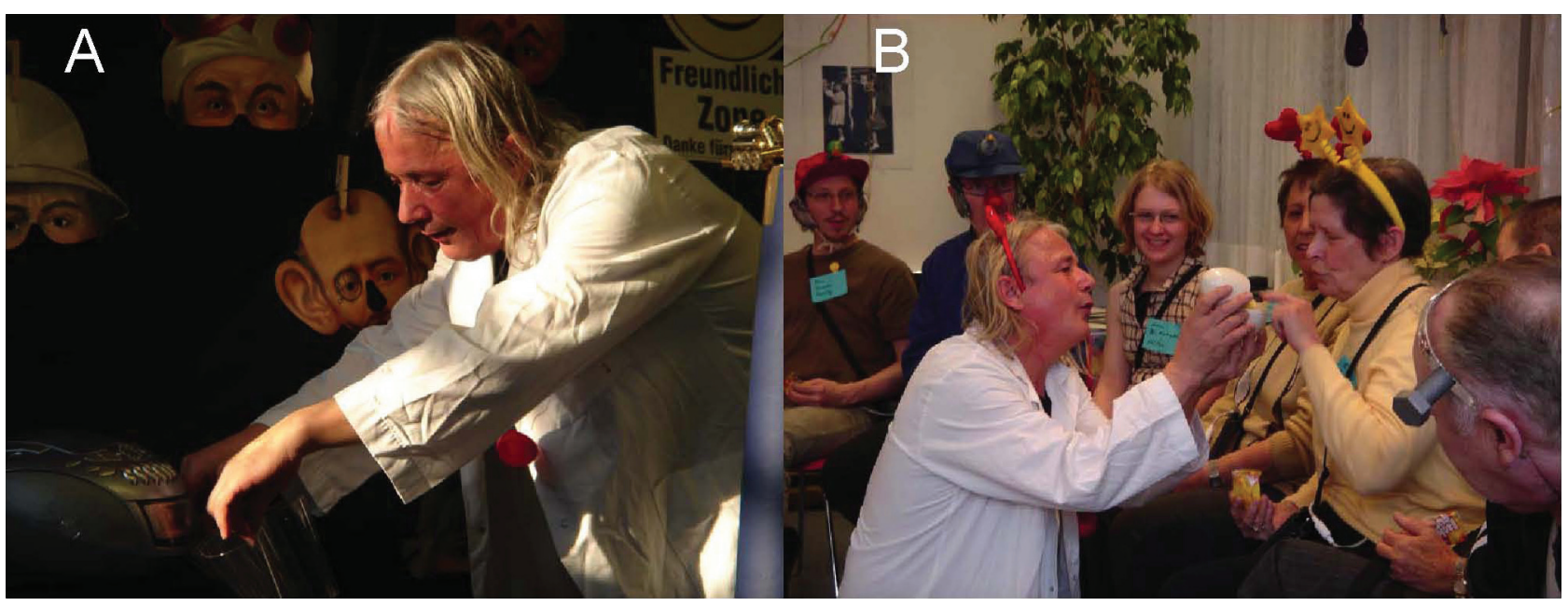

Figure I The humoristic intervention was done by Pello the clown (panel A), a professional humor consultant experienced with patients affected by chronic diseases. Panel B shows a typical scene during the humor intervention. The intervention was done in small groups with roughly 6 participants. Thus, Pello could directly interact with all participants and varied his performance in function of individual responses. The show was optimized to induce as much physical laughter as possible. Different accessories like puppets, and red plastic noses were used during the intervention, which took place on the hospital ward.

video analysis (intensity of smiling and degrees of laughter) were tested for their value as predictors of TLC-response. This was tested by multiple linear regression analysis. Data are generally presented as mean \pm standard deviation. A conventional significance level of 5\% was taken.

\section{Results}

\section{Demographics}

The demographic characteristics of patients and healthy controls are given in Table 1. Within healthy control subjects there were more females, and they were younger. Thirteen of 19 patients had very severe COPD (stage IV according to GOLD), 11/19 (58\%) had a significant hyperinflation (TLC $>120 \%$ ), and all patients had significant air trapping as witnessed by an increased reserve volume (RV).

\section{Safety of humor intervention in patients with severe COPD}

One patient, hospitalized for an exacerbation of a very severe COPD at the time of the study insisted on not applying oxygen during the humor intervention. He normally was under longterm oxygen-therapy. After 10 minutes of intervention he was exhausted, required oxygen, and did not want to continue with the study. Back in his hospital room he felt well and did not experience any discomfort related to the study. The problem was probably not a bronchospasm, but the fact that laughing led to increased oxygen and ventilatory demands. None of the other participants suffered neither from bronchospasm nor respiratory discomfort during the whole 24 hours.

\section{Effect of the humor intervention on static lung volumes}

The intervention led to a reduction of TLC in patients with COPD (mean reduction: $0.31 \pm 0.54[-0.36 ; 1.55] \mathrm{mL}, 5 \pm 9$ $[-6 ; 24] \%$, predicted, $p=0.04$, (Figure 2), but not in controls (mean reduction: $0.24 \pm 0.28[-0.10 ; 0.58] \mathrm{mL}, 5 \pm 6[-2 ; 13]$ $\%$, predicted, $\mathrm{p}=0.9)$. The effect was rather short-lived and no longer present 2 hours after the intervention. The responses varied significantly between subjects. Twenty-two (CI 95\% 7 to 46 ) \% (4/18) of patients and 20 (CI 95\% 4 to 56) $\%(2 / 10)$ of healthy individuals reduced their TLC by more than $10 \%$, predicted. The reduction of TLC in responders ranged between 580 and $1550 \mathrm{~mL}$ or 10 and $24 \%$, predicted. When analyzing the responders separately the reduction of TLC was accompanied by a reduction of the residual volume (RV; mean reduction of $992 \pm 448$ [range 460; 1600] mL, $33 \pm 12 \%, \mathrm{p}<0.001$; Figure 3). No change was observed for the functional residual capacity (FRC; mean change $28 \pm 850$ [range $-710-420] \mathrm{mL},-0.8 \pm 21 \%, \mathrm{p}=0.87$ ). The vital capacity (VC) did not change significantly.

\section{Video-analysis and questionnaires for the assessment of psychological wellbeing}

Patients, as well as controls, responded similarly to the humor intervention in terms of smiling and laughing (KruskalWallis $\mathrm{p}=0.18$ ). Responders among patients with COPD smiled more frequently during the intervention compared with nonresponders $(p=0.04)$. 
Table I Characteristics of study participants

\begin{tabular}{|c|c|c|}
\hline Participants & Patients & Controls \\
\hline$\overline{\mathrm{N}}$ & 19 & 10 \\
\hline \multicolumn{3}{|l|}{ Demographics } \\
\hline $\operatorname{Sex}(m / f)$ & $10 / 9$ & $2 / 8$ \\
\hline Age $[y]^{*}$ & $58 \pm 27(3 \mid-84)$ & $32 \pm 14(18-45)$ \\
\hline Height $[\mathrm{cm}]$ & $168 \pm 12$ & $166 \pm 16$ \\
\hline Weight $[\mathrm{kg}]$ & $72 \pm 22$ & $64 \pm 16$ \\
\hline BMI $\left[\mathrm{kg} / \mathrm{m}^{2}\right]$ & $24.1 \pm 3.8$ & $22.1 \pm 2.4$ \\
\hline COPD (Gold I/II/III/IV) & $0 / 0 / 6 / 13$ & NA \\
\hline \multicolumn{3}{|l|}{ Spirometry } \\
\hline $\mathrm{FEV}_{1}[\mathrm{~L} / \mathrm{sec}]^{*}$ & $48 \pm 24(24-72)$ & $105 \pm 28(77-134)$ \\
\hline $\mathrm{FVC}[\mathrm{L}]$ & $74 \pm 33(4 I-108)$ & $109 \pm 24(84-133)$ \\
\hline $\mathrm{FEV}_{1} / \mathrm{FVC}$ & $0.38 \pm 0.15(0.23-0.52)$ & $0.80 \pm 0.09(0.7 I-0.89)$ \\
\hline \multicolumn{3}{|l|}{ Static lung volumes } \\
\hline TLC [\%, Pred.] & $124 \pm 47$ & $103 \pm 22$ \\
\hline TLC $>120 \%[n, \%]$ & $11 / 19(58 \%)$ & $1 / 10(10 \%)$ \\
\hline ITGV [\%, Pred.] & $158 \pm 53$ & $112 \pm 18$ \\
\hline RV [\%, Pred.] & $190 \pm 102$ & $102 \pm 42$ \\
\hline $\mathrm{RV} / \mathrm{TLC}$ & $0.57 \pm 0.19$ & $0.29 \pm 0.08$ \\
\hline Raw [\%, Pred.] & $472 \pm 370$ & $98 \pm 39$ \\
\hline \multicolumn{3}{|l|}{ Diffusion capacity } \\
\hline TLCO [\%, Pred.] & $4 I \pm 15$ & $99 \pm 16$ \\
\hline KCO [\%, Pred.] & $38 \pm 11$ & $80 \pm 10$ \\
\hline
\end{tabular}

Notes: *Data presented as mean \pm SD (range).

Abbreviations: BMI, body mass index; COPD, chronic obstructive pulmonary disease; FEV , forced expiratory volume in one second; FVC, forced vital capacity; KCO, ; RV, residual volume;TLC, total lung capacity;TLCO.

The intervention improved cheerfulness in patients $(p=0.02)$ and controls $(p=0.02)$ without lowering degrees of state seriousness and state bad mood (both ns). The changes in terms of psychological wellbeing of patients with COPD and healthy controls were comparable, but patients with COPD had higher degree of seriousness at baseline. The latter might also be related to the age difference between patients and controls.
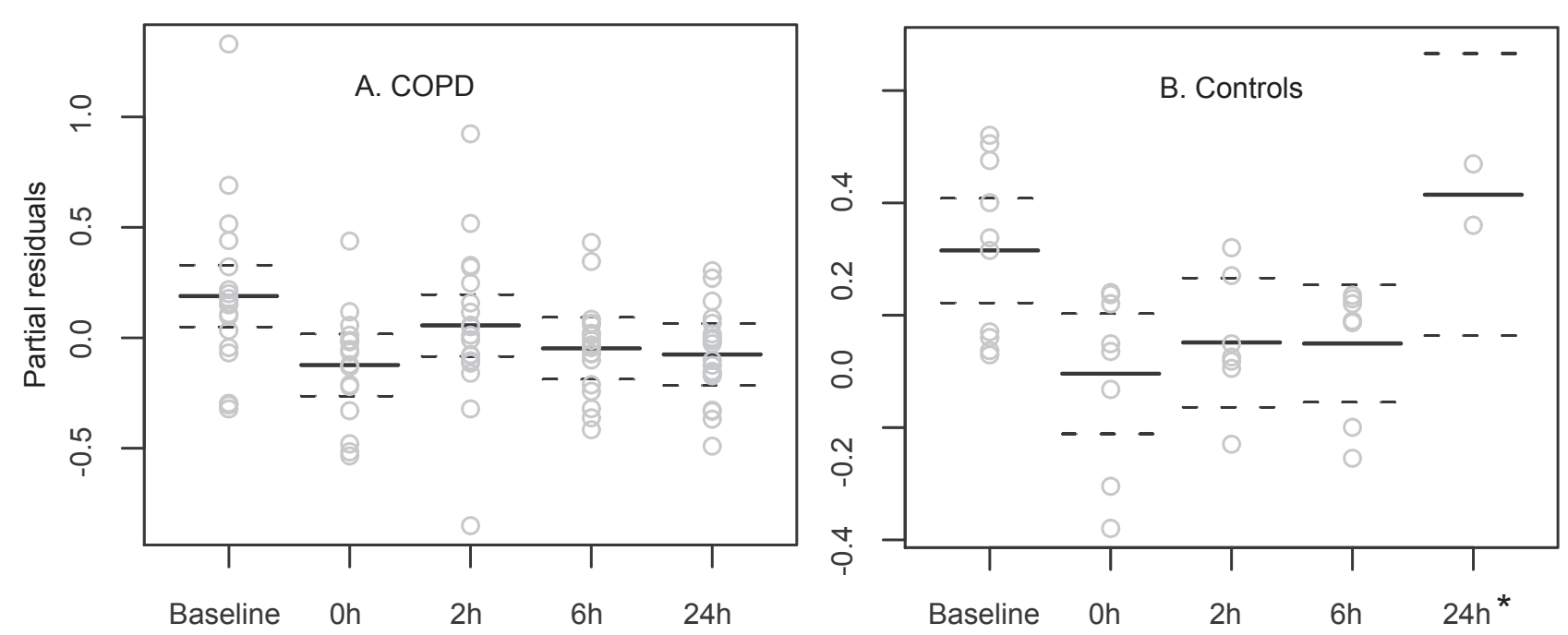

Figure 2 Effect of the humoristic intervention on total lung capacity (TLC) over a time period up to 24 hours in patients with COPD (panel A) and healthy controls (panel B). Shown are responses as partial residuals of the fitted regression model. Responders decreased their TLC for $500 \mathrm{~mL}$ to $\mathrm{more}$ than $\mathrm{I.55} \mathrm{L}$, which can be considered as clinically relevant. On the other hand, two individuals increased their total lung capacity by roughly $10 \%$ or I L over time. During the first 9 hours the patients were not allowed to inhale any medication unless used as a rescue medication (which did not occur). This might explain why some individuals increased their TLC.

*Significant number of missing values for healthy controls at $24 \mathrm{~h}$. 


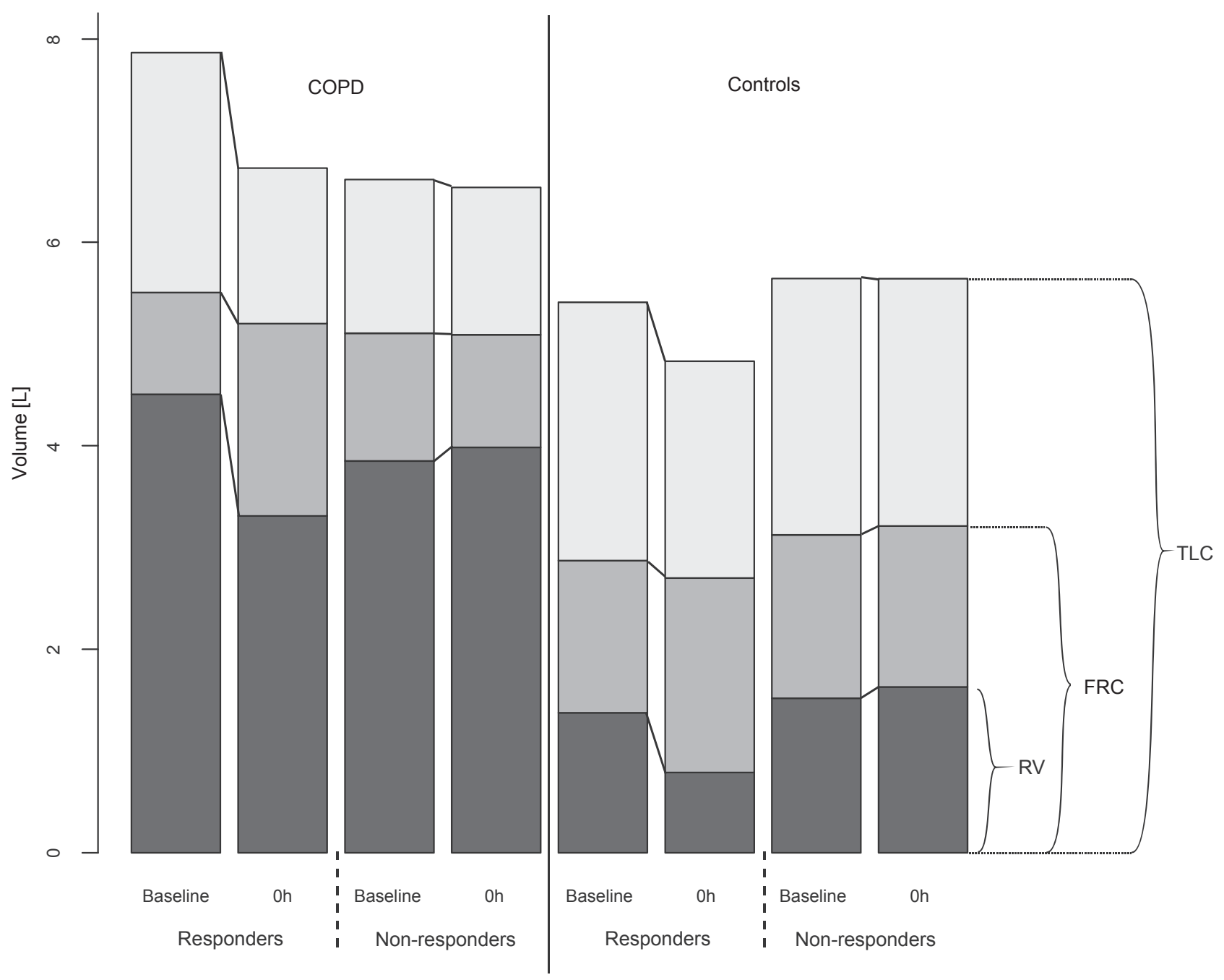

Figure 3 Comparison of the change in static lung volumes between baseline and time 0 hour after the humor intervention in TLC-responders compared to non-responders. Reduction of TLC in responders in response to the humor intervention was primarily due to a reduction of the reserve volume (RV). The functional residual capacity (FRC) and the vital capacity did not change significantly.

\section{Independent predictors of TLC-response}

Multiple linear regression analysis was used in an exploratory fashion to identify independent predictors of response. The frequency of smiling $(\mathrm{p}=0.018)$ and TLC at baseline $(p=0.021)$ proved to be the only independent predictors of TLC-response.

\section{Analysis of real-time breathing pattern}

During the intervention and in order to adapt for a higher demand in oxygen uptake and minute ventilation in response to physical activity and emotion, patients mainly increased their breathing frequency, whereas controls increased their tidal volumes (Table 2). Representative examples of responses to laughter are shown in Figure 4.

\section{Discussion}

A humor intervention with a clown triggering laughter is safe even in patients with severe and very severe COPD and was able to reduce hyperinflation. In $22 \%$ of patients with COPD and $20 \%$ of healthy controls the decrease of TLC was $\geq 10 \%$ and up to $1.55 \mathrm{~L}$. The reduction of TLC was associated with a similar decrease in the reserve volume indicating that the intervention was able to reduce air trapping. Functional residual capacity remained unchanged. Not unexpectedly, but also of potential importance for well-being and quality of life, the humor intervention improved state cheerfulness, but not state seriousness and state bad mood of patients and controls. The frequency of smiling and TLC at baseline were independent predictors of TLC-response. Intense laughter rather increased the dynamic hyperinflation in patients 
Table 2 Results of real-time breathing pattern during the humor intervention

\begin{tabular}{|c|c|c|c|c|c|c|c|}
\hline & & $\begin{array}{l}\text { COPD } \\
(n=I I)\end{array}$ & & & $\begin{array}{l}\text { Controls } \\
(n=9)\end{array}$ & & Sig. \\
\hline & Pre & Clown & Post & Pre & Clown & Post & \\
\hline Breathing rate $[\mathrm{bpm}]$ & $22 \pm 6 *$ & $27 \pm 6$ & $23 \pm 8$ & $17 \pm 4^{*}$ & $26 \pm 8$ & $18 \pm 3$ & \\
\hline Tidal volume $[\mathrm{mL}]$ & $430 \pm 103$ & $510 \pm 155$ & $433 \pm 129$ & $423 \pm 108$ & $578 \pm 164$ & $386 \pm 130$ & $0.05^{\dagger}$ \\
\hline $\begin{array}{l}\text { Minute } \\
\text { ventilation }[\mathrm{L} / \mathrm{min}]\end{array}$ & $8.9 \pm 3.2^{*}$ & $12.7 \pm 1.5$ & $9.3 \pm 2.8$ & $6.5 \pm 1.1 *$ & $14.3 \pm 2.9$ & $6.2 \pm 1.8$ & $0.10^{\dagger}$ \\
\hline I-E ratio & $0.66 \pm 0.12$ & $0.87 \pm 0.17$ & $0.70 \pm 0.17$ & $0.68 \pm 0.13$ & $1.09 \pm 0.09$ & $0.70 \pm 0.09$ & $0.03^{\dagger}$ \\
\hline Phase angle $\left[{ }^{\circ}\right]$ & $12.1 \pm 6.3^{*}$ & $22.6 \pm 7.2$ & $14.8 \pm 6.5$ & $4.9 \pm 1.9 *$ & $15.6 \pm 5.2$ & $5.0 \pm 1.6$ & $0.003^{\dagger}$ \\
\hline Vt irregularity index & $0.16 \pm 0.04 *$ & $0.21 \pm 0.04$ & $0.18 \pm 0.06$ & $0.13 \pm 0.03 *$ & $0.21 \pm 0.06$ & $0.14 \pm 0.03$ & \\
\hline
\end{tabular}

Notes: *Baseline differences between groups $(\mathrm{p}<0.05)$.

tSignificance of interaction between COPD and controls over time.

${ }^{\circ}$ Phase angle between abdominal and ribcage changes.
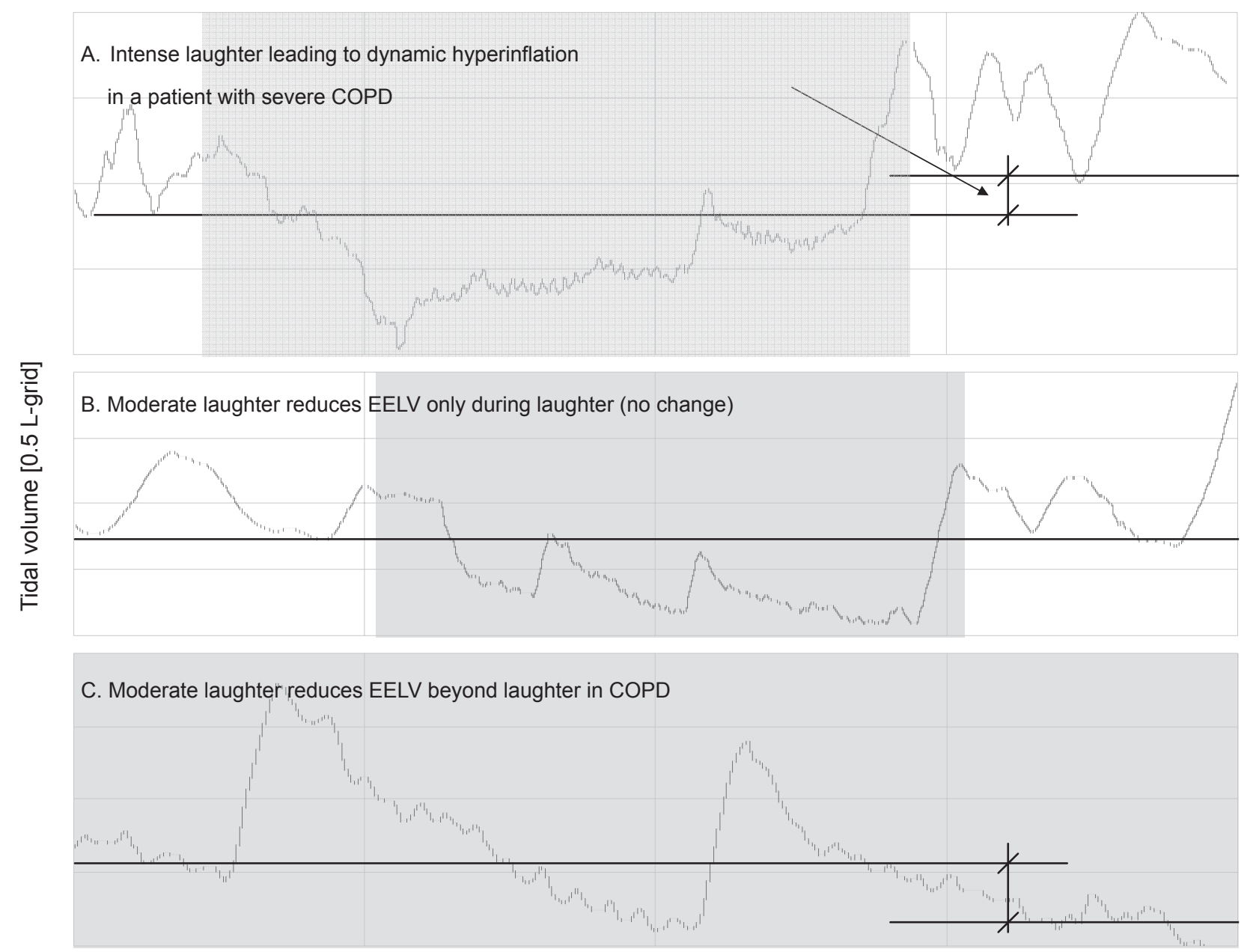

Figure 4 Spirogram from the real-time monitoring of the breathing pattern showing the varying instant effect of laughter on the end-expiratory lung volume (EELV) in patients with COPD. Intense laughter can lead to dynamic hyperinflation in some patients with severe COPD (panel A). Most of the times there was no significant change in the EELV due to a single fit of laughter (panel B). In some instances, particularly as a consequence of smiling, the EELV markedly diminished (panel C). Smiling was able to reduce the EELV in both COPD and controls - at least as an instant effect. 
with severe COPD probably due to the increased minute ventilation and the higher breathing rate on the expense of a shorter expiration time (O’Donnell et al 2001; Gelb et al 2004; Calverley 2006).

The nonrandomized fashion and the lack of crossover design represent limitations of this study, which was conceived as a proof-of-concept study. However, the main finding - the fact that gentle laughter and smiling can reduce total lung volume - is also backed up with the real-time analysis of the breathing pattern during the intervention. The humor intervention with a clown represents a nonstandardized procedure when compared with individual laboratory manipulations, eg, employing a humorous videotape. On the other hand, the clown could directly interact with each individual in order to optimize the likelihood of subjects laughing as much as possible. This could prevent the possibility that some individuals would not laugh at all, as might be the case during a more standardized intervention. Therefore, the lack of a strict standardization might even represent strength and not a weakness of this trial. Also, smiling/laughter and psychological responses were taken as quantitative variables when analyzing the response patterns.

What happens exactly to the lung mechanics during smiling and laughter? Derived from the analysis of realtime breathing pattern during the intervention smiling and laughter can start at any point of a normal tidal volume breathing cycle. The start is characterized by an abrupt expiratory effort, which is followed by fits of expiratory saccades of variable length. During these periods the endexpiratory lung volume is typically diminished compared to tidal breathing. Short, but often rapid and efficient inspirations occur between expiratory saccades. During smiling and laughter expiration is prolonged compared to inspiration. But, what might make the difference between smiling and laughter? The differences are two-fold: vocalization leading to higher positive airway pressures, and activation of additional muscles groups translating to an increased ventilatory demand and oxygen consumption (O'Donnell 2001; Ruch and Ekman 2001). In contrast to laughing, smiling consists of a mostly passive maneuver including low-level rhythmic contractions of abdominal muscles, relaxation of the diaphragm, prolonged expiration, neither of which should produce significantly increased ventilation nor oxygen consumption. For higher intensities of laughter, there is an increased demand for ventilation and oxygen consumption. Increased minute ventilation is known to lead to an increase of the dynamic hyperinflation of patients with COPD (O’Donnell 2001; Gelb et al 2004).
In conclusion, a humor intervention was able to reduce hyperinflation in patients with severe and very severe COPD. Response was mainly associated with smiling and a higher degree of hyperinflation. The results of this proof-of-concept study need to be validated by a randomized cross-over study, especially for a more reliable appreciation of the effect size and duration. If confirmed, a smiling-derived breathing technique could complement the technique of pursed-lips breathing, and enrich the repertoire of patients with symptomatic airway obstruction to better cope with breathlessness (Gosselink 2004). Furthermore this could be achieved anywhere and at any time at no costs and with no drug-induced side effects. On the other hand, therapeutic approaches combining breathing technique with an emotional intervention might be preferable and more likely to be effective.

"Give COPD patients a smile!"

\section{Acknowledgements}

The study could not have been conducted without the help of the study participants, ie, healthy controls and patients with severe COPD. We particularly thank Mrs. Trupty Chhajed, Mrs. Monika Kaufmann, and Dr. Ingrid Carlen Brutsche, who actively supported the study with technical and administrative help. We are also grateful to Mrs. Erika Süess, Mrs. Esther Kaufmann, Mrs. Irene Schönenberger, Mrs. Sibylle Blaser, and Mrs. Yaël Müller for their support during the weekends of data collection. Finally, we would like to thank Iwana Städeli for the coding of the 30 hours of video tapes.

\section{Disclosure}

The study was supported by an unrestricted research grant by AstraZeneca, Switzerland, and internal research funds of the University Hospital Basel. The research was conducted completely independent from the funding institutions. There are no conflicts of interest.

\section{References}

[ATS] American Thoracic Society. 1991. Lung function testing: selection of reference values and interpretative strategies. American Thoracic Society. Am Rev Respir Dis, 144:1202-18.

[ATS] American Thoracic Society. 1995. Standardization of Spirometry, 1994 Update. American Thoracic Society. Am J Respir Crit Care Med, 152:1107-36.

Brutsche MH, Downs SH, Schindler C, et al. 2006. Bronchial hyperresponsiveness and the development of asthma and COPD in asymptomatic individuals: SAPALDIA cohort study. Thorax, 61:671-7.

Calverley PM. 2006. Dynamic hyperinflation: is it worth measuring? Proc Am Thorac Soc, 3:239-44.

Ekman P, Friesen WV, Hager J. 2002. The Facial Action Coding System (FACS): A technique for the measurement of facial action. Palo Alto, CA, Consulting Psychologists Press.

Filippelli M, Pellegrino R, Iandelli I, et al. 2001. Respiratory dynamics during laughter. J Appl Physiol, 90:1441-6. 
Gelb AF, Gutierrez CA, Weisman IM, et al. 2004. Simplified detection of dynamic hyperinflation. Chest, 126:1855-60.

Gosselink R. 2004. Breathing techniques in patients with chronic obstructive pulmonary disease (COPD). Chron Respir Dis, 1:163-72.

Herxheimer H. 1978. Should asthmatic patients laugh? Lancet, 2(8101):1209.

Kimata H. 2004. Effect of viewing a humorous vs. nonhumorous film on bronchial responsiveness in patients with bronchial asthma. Physiol Behav, 81:681-4.

Liangas G, Yates DH, Wu D, et al. 2004. Laughter-associated asthma. $J$ Asthma, 41:217-21.

Miller MR, Crapo R, Hankinson J, et al. 2005. General considerations for lung function testing. Eur Respir J, 26:153-61.

O'Donnell DE. 2001. Ventilatory limitations in chronic obstructive pulmonary disease. Med Sci Sports Exerc, 33(7 Suppl):S647-55.

O’Donnell DE, Revill SM, Webb KA, et al. 2001. Dynamic hyperinflation and exercise intolerance in chronic obstructive pulmonary disease. $\mathrm{Am}$ J Respir Crit Care Med, 164(5):770-7.
Pauwels RA, Buist AS, Calverley PM, et al. 2001. Global strategy for the diagnosis, management, and prevention of chronic obstructive pulmonary disease. NHLBI/WHO Global Initiative for Chronic Obstructive Lung Disease (GOLD) Workshop summary. Am J Respir Crit Care Med, 163:1256-76.

Ruch W, Ekman P. 2001. The expressive pattern of laughter. In: Kaszniak AW ed. Emotion, qualia, and consciousness. Tokyo, Word Scientific Publisher: 426-43.

Ruch W, Köhler G. 1999. The measurement of state and trait cheerfulness. In: Mervielde I, Deary I, De Fruyt F, et al. eds. Personality Psychology in Europe: Theoretical and Empirical Developments. Tilburg, University Press. 7:67-83.

Sarafino EP, Dillon JM. 1998. Relationships among respiratory infections, triggers of attacks, and asthma severity in children. $J$ Asthma, $35: 497-504$. 